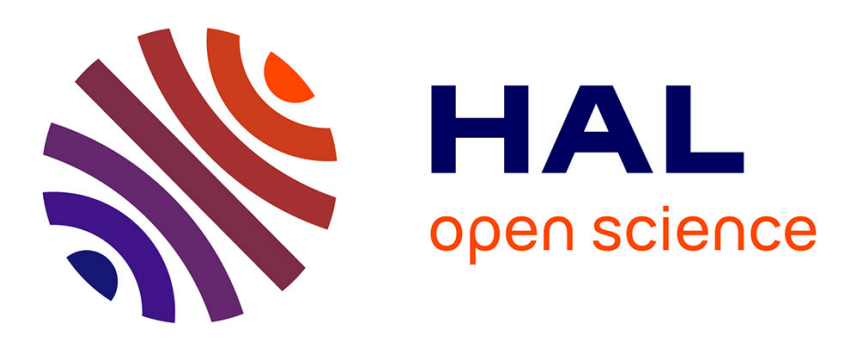

\title{
Theoretical Study of Optimal Positioning of Segregating Component Input into Continuous Mixer of Solids
}

\author{
Vadim Mizonov, Henri Berthiaux, Cendrine Gatumel
}

\section{To cite this version:}

Vadim Mizonov, Henri Berthiaux, Cendrine Gatumel. Theoretical Study of Optimal Positioning of Segregating Component Input into Continuous Mixer of Solids. Particulate Science and Technology, 2015, 33 (4), pp.339-341. 10.1080/02726351.2014.970312 . hal-01609206

\section{HAL Id: hal-01609206 https://hal.science/hal-01609206}

Submitted on 17 May 2018

HAL is a multi-disciplinary open access archive for the deposit and dissemination of scientific research documents, whether they are published or not. The documents may come from teaching and research institutions in France or abroad, or from public or private research centers.
L'archive ouverte pluridisciplinaire HAL, est destinée au dépôt et à la diffusion de documents scientifiques de niveau recherche, publiés ou non, émanant des établissements d'enseignement et de recherche français ou étrangers, des laboratoires publics ou privés. 


\title{
Theoretical Study of Optimal Positioning of Segregating Component Input into Continuous Mixer of Solids
}

\author{
VADIM MIZONOV, ${ }^{1}$ HENRI BERTHIAUX, ${ }^{2}$ CENDRINE GATUMEL ${ }^{2}$ \\ ${ }^{1}$ Department of Applied Mathematics, Ivanovo State Power Engineering University, Ivanovo, Russia \\ ${ }^{2}$ Ecole des Mines d'Albi-Carmaux, RAPSODEE Centre, Albi, France
}

\begin{abstract}
The objective of the study is to demonstrate theoretically one of the ways of improving the quality of continuous mixing of segregating particulate solids. The objective function of optimization is the standard deviation of segregating component distribution over the mixer's cross-section at the mixer outlet, the optimization parameter being the position of segregating component input. It is shown that the input of the component into the position that is optimized over the length of the mixer allows improving the mixing quality. The gain of optimization depends on the rate of segregation and grows with its increase.
\end{abstract}

Keywords: continuous mixing, input position, Markov chain, matrix of transition probabilities, mixing quality, optimization, segregation, state vector

\section{Introduction}

Mixing of solids is a complex process of particle migration inside the operating volume of a mixer that is strongly influenced by particle segregation. It is practically impossible to reach a homogeneous mixture of segregating components, at least in the industrial scale apparatuses. However, it is possible to try to decrease the negative influence of segregation by means of special control of inflows of the components to be mixed. Mathematical modeling of the process helps to understand it better and to search for the ways of improving it.

An appropriate mathematical tool for modeling the process is the theory of Markov chains, which is rather native to the process of mixing because both are related to the evolution of the state of a stochastic system. The basic ideas of application of the Markov chain approach to describing continuous mixing of solids were developed by Berthiaux and Mizonov $(2004,2005)$. Later on, in the paper by Mizonov et al. (2009), a two-dimensional Markov chain model was proposed that allowed describing the crosswise distribution of segregating component. However, these and all other works only used this theory to describe the process and practically never to optimize it. An attempt to use the approach to optimize the continuous mixing process by means of optimal control of segregating component inflow is presented below.

Address correspondence to: Vadim Mizonov, Department of Applied Mathematics, Ivanovo State Power Engineering University, Rabfakovskaya 34, 153003 Ivanovo, Russia. E-mail: mizonov46@mail.ru

\section{A Two-Dimensional Model of Continuous Mixing}

The particulate solids to be mixed are presented as the binary mixture of particles of different size or density that causes the downward segregation of one fraction within another. One of the simplest cell models of continuous mixing is shown in Figure 1a. It can be presented as the two-dimensional array of cells of the size $n \times m$ with transition probabilities shown in Figure 1b. The probabilities $d_{x}$ and $d_{y}$ are related to pure diffusion, the probability $v_{\mathrm{t}}$ is related to transportation of components along the length of the mixer, and the probability $v_{\mathrm{s}}$ is related to the downward segregation of the key component. The transportation transition probability $v_{\mathrm{t}}$ is directly proportional to the dimensional particle flow velocity through a continuous mixer, which, in turn, is the complex parameter combining the particle flow rate, the particle holdup in the mixer, and the residence time of particles. The formulae connecting $v_{t}$ and the process parameters can be found in the papers by Berthiaux et al. (2005) and by Mizonov et al. (2009). Each probability can be interpreted as the part of particles that is transferred from the given cell into the neighboring one during one given time transition due to the corresponding transfer flow.

It is convenient to present the current state of the process as the $n \times m$ state matrix $\mathbf{S m}$, entries of which are the contents of the segregating component in the cells. However, for further mathematical operations, this matrix is to be transformed to the state vector $\mathbf{S}$, in which columns of the matrix Sm must be placed one under another. 


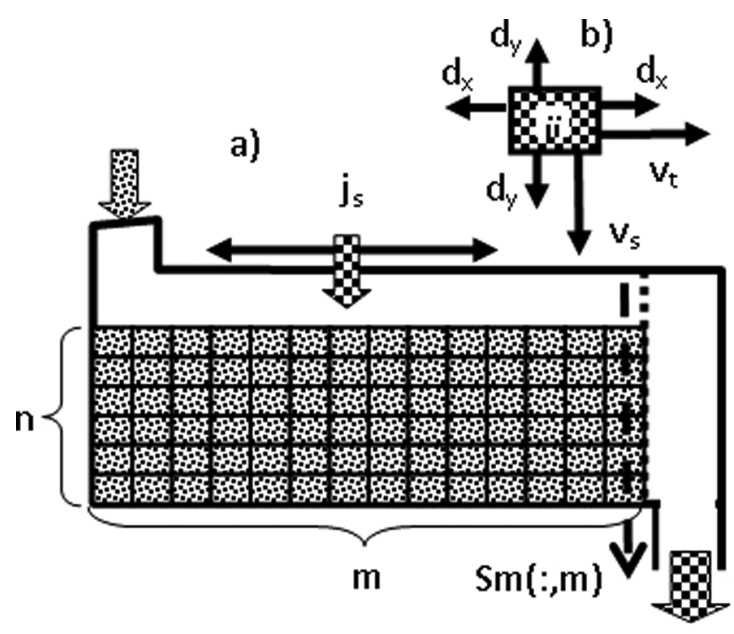

c)

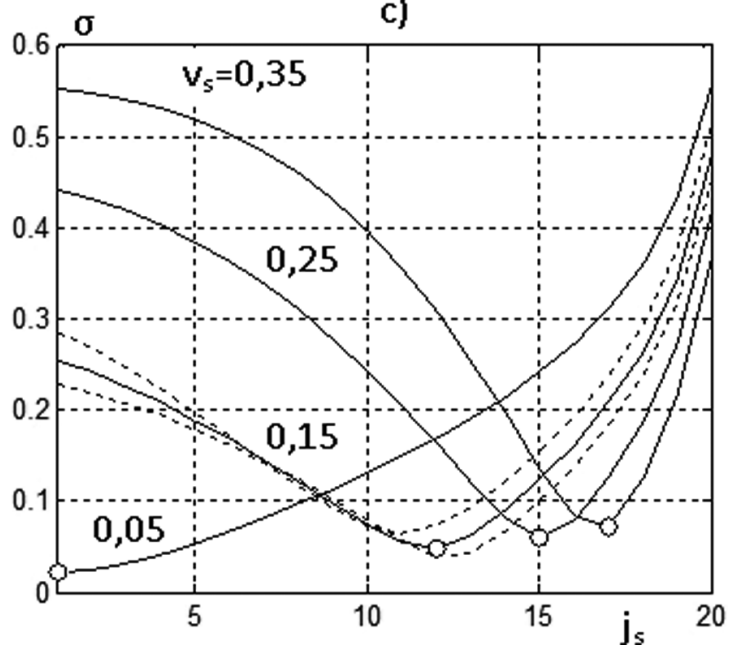

Fig. 1. Schematic presentation of continuous mixing process: (a) Two-dimensional cell model of the process, (b) scheme of transitions from a cell, and (c) dependence of mixing quality on the position of the input of the segregating component at various segregation rates.

Evolution of the state of the process can be described by the recurrent matrix equation

$$
\mathbf{S}^{\mathbf{k}+\mathbf{1}}=\mathbf{P S}^{\mathbf{k}}+\mathbf{S}_{\mathbf{f}}
$$

where $k$ is the time transition number, $\mathbf{S}_{\mathbf{f}}$ is the feed vector that has the size $n m \times 1$ and it has the only nonzero element that corresponds to the number of the cell that the segregating component is fed to, and $\mathbf{P}$ is the matrix of transition probabilities.

The matrix of transition probabilities $\mathbf{P}$ is the $(n m \times n m)$ matrix, entries of which are to be defined from the following relationships:

Upward transitions

$$
P_{(n(j-1)+i-1, n(j-1)+i)}=d_{y}, \quad i=\overline{2, n}, j=\overline{1, m},
$$

Downward transitions

$$
P_{(n(j-1)+i+1, n(j-1)+i)}=d_{y}+v_{s}, \quad i=\overline{1, n-1}, j=\overline{1, m},
$$

Forward transitions

$$
P_{(n(j-2)+I, n(j-1)+i)}=d_{x}, \quad i=\overline{1, n}, j=\overline{2, m},
$$

Backward transitions

$$
P_{(n j+i, n(j-1)+i)}=d_{x}+v_{t}, \quad i=\overline{1, n}, j=\overline{1, m-1} .
$$

All the other entries of the matrix are equal to zero.

It is supposed that the matrix is state independent, i.e., the transition probabilities from a cell do not depend on particle content in this or that particular cell and in the surrounding ones. It is a linear model of the process, and it is supposed to be valid when the amount of segregating key component is relatively small in comparison to the basic component.

It is easy to show that the asymptotic state of the process at $k \rightarrow \infty$ can be calculated as

$$
\mathbf{S}^{\infty}=(\mathbf{I}-\mathbf{P})^{-1} \mathbf{S}_{\mathbf{f}}
$$

where $\mathbf{I}$ is the identity matrix of the same size as $\mathbf{P}$ and the index ${ }^{-1}$ means the inverse of the matrix. It allows obtaining the steady-state distribution of the key component without recurrent calculation by Equation (1). It is necessary to note that Equation (6) is only valid if the matrix $\mathbf{P}$ and the feed vector $\mathbf{S}_{\mathbf{f}}$ are constant.

\section{Results of Optimization}

In usual mixers, the two components are fed together into the cell $(1,1)$. The objective of the process is to make the mixture at the outlet (i.e., in the last column of the array) as homogeneous as possible. At no segregation, the length of the mixer serves to provide the proper mixing time that is necessary for achieving a homogeneous mixture. However, the downward segregating component is capable of reaching the bottom of the mixer if its length is too long and is capable of staying near its top if the length of the mixer is too short. It is possible to agree the mean trajectory of the component and its mean residence time by moving the segregating component input $j_{\mathrm{s}}$ over the mixer's length.

The results of such optimization for the array $12 \times 20$ are shown in Figure 1. The standard deviation $\sigma$ of the distribution of the segregating component over the last column of the array of cells was used to characterize the mixture quality. It can be clearly seen that the optimal position $j_{\mathrm{s}}$ that provides the maximum mixing quality does exist. This position depends on the segregation rate, and it moves to the mixer inlet when the rate decreases. The point of each curve for $j_{\mathrm{s}}=1$ corresponds to the feed to the mixer's inlet. Comparison of the points for different segregation rates shows how strongly the mixture quality depends on the segregation rate. However, if the feed is arranged into the optimal position, the mixture quality not only significantly improves but also gets far less dependent on the segregation rate. This situation happens very often in optimization problems when the influence of the process parameters is "washed out" near the optimal points. The solid curves were calculated at 
$d_{x}=0.1$ (longwise mixing) and $d_{y}=0.25$ (crosswise mixing). The dashed lines near the solid curve for $v_{\mathrm{s}}=0.15$ were calculated for $d_{y}=0.15$ and $d_{y}=0.35$. It can be seen that the influence of intensity of crosswise mixing also exists, but it is much weaker than the influence of the segregation rate.

It is obvious that the optimal solution can be easily implemented technically by installing an additional movable inlet for segregating component.

\section{Conclusions}

It is shown that the feed of segregating component to the intermediate optimal position over the mixer's length allows improving the mixture quality at the end of the mixer. The gain of optimization grows with the increase of the segregation rate. It is hardly possible to hope that the gain predicted by the model can be directly achieved in practice. However, for the strongly segregating component, the predicted gain is so high that it is realistic to expect that, independently on the error of prediction, a real gain will be obtained.

\section{Funding}

The authors are thankful to the Russian Foundation for Basic Research (Grant no. 15-08-01684) for financial support of the work.

\section{References}

Berthiaux, H., and V. Mizonov. 2004. Applications of Markov chains in particulate process engineering: A review. The Canadian Journal of Chemical Engineering 85:1143-1168.

Berthiaux, H., V. Mizonov, and V. Zhukov. 2005. Application of the theory of Markov chains to model different processes in particle technology. Powder Technology 157:128-137.

Mizonov, V., H. Berthiaux, C. Gatumel, E. Barantseva, and Y. Khokhlova. 2009. Influence of crosswise non-homogeneity of particulate flow on residence time distribution in a continuous mixer. Powder Technology 190:6-9. 